\title{
A COMÉDIA COMO ESPELHO: THOMAS RANDOLPH E A RECEPÇÃO ELISABETANA DO
}

\section{TEATRO ANTIGO}

\author{
Milton L. Torres ${ }^{1}$ \\ Doutor em Letras Clássicas pela USP \\ miltntorres@gmail.com
}

Pode-se dizer do dramaturgo Thomas Randolph (1605-1635) a mesma coisa que a pesquisadora Katharine P. Frescoln disse acerca do diplomata Thomas Randolph (1523-1590), ${ }^{2}$ que pode, mas não deve ser confundido com ele: "poucas pessoas conhecem Randolph como outra coisa a não ser um nome" (FRESCOLN, 1971, p. v). Felizmente, porém, temos a nota biográfica publicada por Duport (1875), no volume em que coletou as obras completas de Randolph, e a tese de Richek (1982), que preenchem muito bem a lacuna que a falta de uma biografia de Randolph deixaria nos estudos sobre o teatro elisabetano. Por intermédio delas, sabemos que Ben Johnson adotou o jovem poeta como seu protégé. Só o fato de Randolph cair nas graças de um crítico tão severo já nos mostra que Randolph deve ser mais do que apenas um nome. Além disso, a própria qualidade das peças supérstites do dramaturgo nos garante isso. Não fosse a morte prematura, é possível que Randolph tivesse superado, inclusive, o mentor, como era a expectativa geral por ocasião do falecimento de Johnson, consoante os versos de G. W. Joan (apud RICHEK, 1982, p. 1): ${ }^{3}$

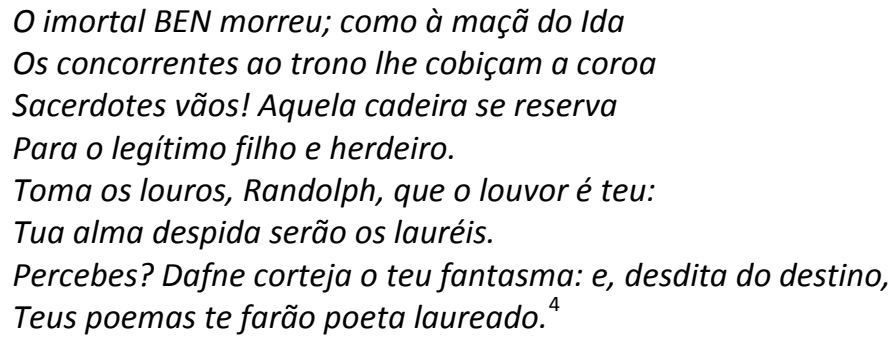

\footnotetext{
1 Milton L. Torres é doutor em Letras Clássicas pela USP, PhD em Arqueologia Clássica pela Universidade do Texas e pós-doutor em Estudos Literários pela UFMG. Atualmente, é professor do Mestrado Profissional em Educação do Centro Universitário Adventista de São Paulo (UNASP), onde também coordena os cursos de Letras e Tradutor.

${ }^{2}$ Esse Randolph foi o embaixador da rainha Elizabeth na Escócia entre 1559 e 1586, intermitentemente, o que Frescoln (1971, p. v) chama de "tarefa estratégica num período significativo".

3 Todas as traduções no texto são minhas.

Immortal BEN is dead; and as that ball

On Ida toss'd, so is his Crowne by all

The Infantry of sit. Vaine Priests! That chaire

Revista "O Teatro Transcende" Departamento de Artes - CCEAL da FURB - ISSN 2236-6644 - Blumenau, Vol. 22, № 1, p. 1 -2, 2017
} 
A despeito da inegável popularidade entre seus contemporâneos e da impressionante reputação que Randolph granjeou durante a vida tanto como poeta quanto como dramaturgo, ${ }^{5}$ tendo inclusive discursado em latim, em 1632, na formatura de mestrado de John Milton (RICHEK, 1982, p. 7), ${ }^{6}$ o jovem escritor não conseguiu impressionar os historiadores do drama e as gerações posteriores de poetas. ${ }^{7}$

O ensino do grego na Universidade de Cambridge começou apenas em 1518 (BUSH, 1946, p. 113-114) e, tanto quanto se saiba, a Randolph cabe a honra de ter traduzido, pela primeira vez, uma peça de Aristófanes para a língua inglesa. Entre 1626 e 1628, quando ainda era aluno do Trinity College, o dramaturgo traduziu a peça Pluto para que fosse encenada pelos colegas. À moda da época, Randolph anglicizou o texto, dando-Ihe o título de Hey for honesty, down with knavery ("Viva a honestidade, fora com a fraude"), ${ }^{8}$ situando-a na própria Inglaterra e acrescentando-Ihe vários personagens tipicamente ingleses. Das mudanças que fez no enredo, a mais audaciosa foi transformar o sacerdote de Zeus no próprio Papa. ${ }^{9}$

No entanto, o sucesso de Randolph não pode ser medido apenas por suas traduções e seus esforços acadêmicos. Há relatos de que a originalidade de suas peças obteve reconhecimento imediato. O drama Amyntas, uma bem sucedida experiência teatral com o gênero bucólico, numa "mistura de tragicomédia, comédia romântica, farsa e burlesco" (HERRICK, 1955, p. 169), foi encenado diante do rei e da rainha,

Is only fit for his true Sonne and Herie.

Reach here the Lawrell: Randolph, tis thy praise:

Thy naked Soull shall well become the Bayes.

See, Daphne courts thy Ghost: and spite of fate,

Thy Poems shall be poet Laureat.

${ }^{5}$ Coiro (2004, p. 614) o considera "o mais talentoso dramaturgo acadêmico do século XVII". Para ThornDrury (1929, p. viii), Randolph deixou após si "uma reputação mais considerável do que a de qualquer outro escritor de sua época".

${ }^{6}$ Naquela época, o costume em Cambridge era que o formando mais destacado do ano anterior fizesse um discurso, em nome dos ex-alunos, na formatura da seguinte turma de mestrado.

${ }^{7}$ Para uma análise da possível influência de Randolph sobre Milton, veja-se Coiro, 2004.

${ }^{8}$ Richek (1982, p. 4-5) lamenta que a peça sobreviva apenas numa versão bastante modificada por um revisor anônimo que assina com as iniciais F.J. De fato, a versão do drama que chegou a nós foi publicada com o título original em grego, mas com o subtítulo A pleasant comedie, entituled Hey for honesty, down with knavery - translated out of Aristophanes' Plutus by Thomas Randolph, augmented and published by F.J. in 1651. Nesse formato, a peça tem mais de duas vezes o tamanho de Pluto e várias cenas adicionais.

${ }^{9}$ Hall $(2007$, p. 66-92) trata brevemente dessa peça ao analisar a recepção de Aristófanes na Inglaterra a partir de 1650.

Revista "O Teatro Transcende" Departamento de Artes - CCEAL da FURB - ISSN 2236-6644 - Blumenau, Vol. 22, № 1, p. 1 -2, 2017 
provavelmente em $1631 .^{10}$ Outra experiência dramática, desta vez criando uma comédia, no estilo de Plauto, sobre a história do filho pródigo, Jealous lovers ("Amantes ciumentos") foi encenada, em 1632, por ocasião da visita do rei à Universidade de Cambridge, onde Randolph possuía uma cátedra. Richek (1982, p. 164) a considera sua comédia mais conhecida e a de "estilo mais maduro, decoroso e clássico". Na primeira fase de sua carreira, escreveu, porém, peças mais modestas que se voltaram principalmente para a sátira das circunstâncias e eventos ocorridos na Universidade de Cambridge, onde viveu a maior parte de sua vida adulta. Entre estas, incluem-se o curto drama Aristippus ou The jovial philosopher ("O filósofo jovial"), considerada uma de suas criações mais populares (FARMER, 2005, p. 154), ${ }^{11}$ o monólogo The conceited peddlar ("O mascate convencido"), e Salting ("Trote"), peça sobre uma cerimônia de iniciação, da qual temos apenas um manuscrito incompleto.

O interesse por Randolph tem aumentado nos últimos anos, embora seja difícil precisar se isso se deve a seu talento como poeta, de acordo com Saintsbury (1905, p. 413), ou a seu gênio dramático, como declara Dibdin (1800?, v. 4, p. 47). O próprio título deste trabalho sugere que nós o estudaremos aqui por suas conexões com o teatro elisabetano, especialmente no que estas dizem respeito àquela que Saintsbury (1905) e Richek (1982, p. 160-161) consideram sua obra-prima, ${ }^{12}$ The muses' lookingglass ("O espelho das musas"), inspirada na Ética a Nicômaco, de Aristóteles. O filósofo era especialmente admirado pelo dramaturgo que, em seu poema By Cham's fair streams ("Às margens plácidas do Cham"), se referiu a ele como "o grande Tutor do maior dos reis".

\section{O ESPELHO DAS MUSAS}

A peça The muses' looking-glass foi apresentada, em dezembro de 1630, na inauguração de um teatro de Londres, por ocasião do cancelamento da proibição às aglomerações públicas que a praga havia imposto. Seu teor moral e didático impediria

\footnotetext{
${ }^{10}$ Greg (1910) o considera um dos três melhores dramas bucólicos do teatro inglês.

${ }^{11}$ Farmer (2005, p. 329-330) a chama ainda de the fastest-selling play in the entire early modern English book trade.

${ }_{12}$ Dibdin (1800?) prefere Jealous lovers.

Revista "O Teatro Transcende" Departamento de Artes - CCEAL da FURB - ISSN 2236-6644 - Blumenau, Vol. 22, № 1, p. 1 -2, 2017
} 
certamente que ela obtivesse hoje o mesmo sucesso que teve em sua época. Ainda assim, as propensões ecléticas daquele período e a carreira docente de Randolph contribuíram para a produção de uma obra-prima mesmo quando julgada com base nos padrões de épocas posteriores. ${ }^{13}$ Trata-se de uma morality play ("peça moralizante"), com foco mais intelectual e ético do que religioso. Nas palavras de Richek (1982, p. 197),

[A peça] é o produto do Renascimento no sentido de que há inerente a ela a crença no poder persuasivo da comédia. Nessa peça, o meio, a comédia, é tanto a mensagem quanto um exemplo de como esta opera. A peça é também um produto do Renascimento no sentido de que contém um conceito clássico de virtude e vício, tirado de Aristóteles... mundos distantes do conceito medieval mais primitivo, embora mais poderoso, de que o ser humano está à mercê dos elementos e da tentação dos vícios e de outras forças do mal neste vale de lágrimas.

A estrutura básica da peça é tripartite: o primeiro ato, que termina com a mascarada dos vícios; os atos II a IV, que constituem a parte mais inovadora da peça; e o quinto ato, que começa com a mascarada das virtudes e representa uma imagem invertida do primeiro ato. Por uma questão prática, apresento, em seguida, o resumo que Richek (1982, p. 26) oferece da peça:

\begin{abstract}
A seção principal dessa peça de estrutura complexa consiste de uma série de debates entre dois, às vezes três, personagens alegóricos que representam os dois vícios que figuram como extremos opostos de cada uma das virtudes aristotélicas. Cólax, o bajulador que age como alcoviteiro de todos os vícios, depois de seu próprio debate com o irritadiço Díscolo, o outro extremo da virtude da Cortesia, acrescenta uma terceira voz, às vezes, durante os debates entre os outros extremos das onze virtudes restantes. Díscolo contribui com variedade e muito humor. A estrutura complexa de Randolph também inclui a disputa corrente entre Róscio, um ator, e dois puritanos sobre o valor moral do palco, especialmente a comédia. Essa discussão, a moldura da peça, determina-lhe o tema. Outra parte da comédia é criada a partir da combinação de declamação e disputa por parte de personificações dos gêneros teatrais: comédia, tragédia, mimo, sátira (escrita satyr por Randolph). Além disso, a peça apresenta duas mascaradas: uma das virtudes e outra dos vícios. Quando a cortina desce, o público terá verdadeiramente experimentado a comédia como corretor ético e abominação, embora os dados de Randolph estejam definitivamente viciados. Será difícil que a plateia esteja menos convencida, no final, do que os tacanhos puritanos reformados, que apareceram previamente no palco, do grande valor moral da comédia.
\end{abstract}

13 Além disso, Richek (1982, p. 170) explica que havia verdadeira veneração por Aristóteles em Cambridge, naquela época, a não ser nos círculos puritanos.

Revista "O Teatro Transcende" Departamento de Artes - CCEAL da FURB - ISSN 2236-6644 - Blumenau, Vol. 22, № 1, p. 1 -2, 2017 
Assim, o ato I apresenta a conversa do ator Róscio com Bird e Flowerdew, ${ }^{14}$ comerciantes puritanos que infamam a frequência aos teatros como práticas pecaminosas, o primeiro dos quais chama os teatros de "lojas de Satanás" (shops of Satan), enquanto que Flowerdew se refere ao fato de seu vigário os chamar de "colégios da transgressão, onde os sete pecados capitais são estudados" (the colledges of transgression wherein the seven deadly sinnes are studied). ${ }^{15}$ Esses personagens objetam a que Róscio pretenda usar os artigos que vendem no palco e tentam convertê-lo. Em sua defesa da arte teatral, o ator explica que os atores vivem do vício da mesma forma que os médicos vivem da doença: para curá-los. Ele os desafia, portanto, a assistir ao espetáculo, com o que eles relutantemente concordam. Róscio se dirige à plateia e explica que o drama é o espelho das musas onde a alma pode verificar seu estado de saúde. A cena seguinte mostra a disputa entre duas irmãs, Tragédia e Comédia, pela primazia na educação dos cidadãos. Tragédia alega, entre outras coisas, que o riso não é objeto apropriado para a poesia e se apresenta como impedimento para o crime já que representa graficamente as consequências do vício. Comédia se defende, afirmando que só o humor é capaz de impedir o comportamento estulto. Entram em cena, então, Mimo e Sátira, ambos alegando o valor educativo do ridículo. Mimo usa o argumento de que os espartanos conseguiam educar os filhos para que não se tornassem ébrios simplesmente lhes mostrando helotas embriagados. Diante disso, Tragédia propõe que os quatro personagens cessem as hostilidades mútuas e juntem forças para reprovar o vício. Para isso, Mimo é incumbido de conduzir uma "mascarada", espécie de dança rude, sobre os sete pecados capitais. Infelizmente, há problemas crítico-textuais em relação a essa parte da peça, a mascarada ficando limitada a uma canção. O primeiro ato termina com a saída de

14 Segundo o livro III, da Arte gramatical, de Diomedes, havia, na antiguidade, um ator de comédias, cujo nome era Róscio Galo, "precípuo histrião, porque possuía os olhos tortos e não pronunciava suficientemente decoroso os papéis a não ser como parasito". A escolha do nome do personagem, provavelmente, constitui uma referência erudita de Randolph à comédia romana.

15 De acordo com Farmer (2005, p. i), as peças de Randolph promoviam um virulento antipuritanismo, embora evitassem ataques polêmicos à igreja católica. Sua peça Aristippus, por exemplo, representa os puritanos como "iconoclastas violentos" (FARMER, 2005, p. 24). 
todos, inclusive dos puritanos que assistiam ao espetáculo. Antes de sair, Róscio pede a misericórdia do público e enfatiza o tema aristotélico da peça.

A partir do segundo ato, Cólax e Díscolo, sob os olhares atentos de Róscio e seus acompanhantes, lideram a parada dos extremos das virtudes, uma das poucas quebras na sequência em que Aristóteles apresenta sua lista de virtudes na Ética a Nicômaco, onde esses dois extremos aparecem por último. A sequência obedece, nos atos II a III, a ordem proposta por Aristóteles, mas, provavelmente sob a influência de Teofrasto (Characteres), ${ }^{16}$ ocorrem variações de ordem e alterações no tratamento a partir do quarto ato:

$$
\begin{aligned}
& \text { Delius - Fortitude - Aphobius } \\
& \text { Anaisthetus - Temperance - Acolastus } \\
& \text { Aneuletherus - Liberality - Asotus } \\
& \text { Microprepes - Magnificence - Banausus } \\
& \text { Micropsychus - Magnanimity - Caunus }
\end{aligned}
$$

Luparus - Apparell (em vez de Pride ou Ambition) - Philotimia

$$
\text { Anaiskyntia - Modesty - Kataplectus }
$$

Justice Nihil e seu servo Minus - Justice - Justice Nimis e seu servo Plus

$$
\begin{gathered}
\text { Agroicus - Urbanity - Bomolochos } \\
\text { Aorgus - Meekness - Orgylus } \\
\text { Eiron - Truth - Alazon }{ }^{17}
\end{gathered}
$$

O que se percebe nesses confrontos de vícios é que eles disputam o direito ao nosso riso. Dessa forma, como afirma Richek (1982, p. 198-199),

O riso, em geral de reconhecimento, nos liberta de quaisquer ilusões que possamos entreter quanto à vantagem de cultivar algum vício. Tanto a comédia é um espelho normativo quanto o segura para que a plateia (isto é,

\footnotetext{
${ }_{17}^{16}$ A obra de Teofrasto tinha sido recentemente redescoberta, em 1592.

Temeroso - Corajoso - Temerário

Apático - Moderação - Desregrado

Sovina - Liberalidade - Pródigo

Mesquinho - Magnificência - Esbanjado

Pusilânime - Magnanimidade - Afoito

Opulento - Vestuário (em vez de Orgulho ou Ambição) - Ostentação

Despudor - Modéstia - Encabulado

Magistrado Nada e seu servo Menos - Justiça - Magistrado Demais e seu servo Mais

Rústico - Urbanidade - Gaiato

Pacato - Mansidão - Genioso

Irônico - Verdade - Impostor

Revista "O Teatro Transcende" Departamento de Artes - CCEAL da FURB - ISSN 2236-6644 - Blumenau, Vol. 22, № 1, p. 1 -2, 2017
} 
os seres humanos) enxergue quais são os extremos de cada virtude e quão mais sensato é nos esforçarmos para alcançar a média dourada representada por Dona Mediocridade e suas virtuosas filhas.

A título de exemplificação, mencione-se que, no ato III, cena IV, duas figuras que personificam extremos de verdade discutem sobre a influência de Homero em sua existência. A primeira tradução das obras completas de Homero para a língua inglesa, publicada por George Chapman, em 1616, presta detalhada atenção ao que o tradutor convencionou chamar de as qualidades de ironia e escárnio da llíada e da Odisseia. De acordo com Wolfe (2008), sua preocupação com as qualidades irônicas de Homero o ajuda a resolver aparentes incongruências na narrativa. Por outro lado, sua preocupação com o escárnio nas mesmas obras o ajuda a estabelecer sua autoridade crítica em relação aos editores e tradutores anteriores. No prefácio e em seus comentários, Chapman procura estabelecer as diferenças e semelhanças entre essas duas perspectivas. A tradução de Chapman acaba funcionando como pano de fundo contra o qual se discute, pela primeira vez, em língua inglesa, os contrastes entre eironeia ("ironia") e alazoneia ("impostura"). Cabe a Thomas Randolph o papel de precursor dessa discussão.

Na cena, o primeiro personagem recebe o nome de Alazon ("impostor") e reivindica, tanto para si quanto para seu interlocutor, um lugar na genealogia do grande poeta da epopeia grega. Com uma vanglória persistente, vê a si mesmo como o Heitor de sua época e a seu interlocutor como um novo Aquiles. O segundo personagem, a quem cabe o nome de Eiron ("irônico"), recusa esse privilégio, afirmando, a despeito de sua reconhecida valentia, que não é nenhum Aquiles. Os apartes de um terceiro personagem denominado Cólax ("bajulador") deixam claro que os dois personagens erram, respectivamente, um por defender uma falsidade e o outro, por negar uma verdade. Assim, na conversa que entabulam, na cena IV, Alazon e Eiron reivindicam a origem homérica para o contrário dos vícios retóricos que representam. 
À medida que se referem a seus autores favoritos, Eiron declara que não existe poesia além da Ilíada. ${ }^{18}$ Como compete à natureza do impostor, Alazon protesta que ele, e não Eiron, faria jus ao título de verdadeiro herdeiro da llíada. Contudo, sua alegação de que a llíada é o berço da impostura e não da ironia carece de sustentação pelo fato de que, em primeiro lugar, espera-se que um impostor reivindique privilégios que não merece e, em segundo lugar, contraria o tratamento que Aristóteles confere à impostura e à ironia em sua Ética a Nicômaco 1108a23, onde afirma que ninguém pode distinguir facilmente as dissimulações da pessoa irônica daquelas do impostor (WOLFE, 2008, p. 152). Por isso, a cena termina sem a resolução do questionamento se o épico Homero proporcionou a gênese da impostura, da ironia, de ambas, ou de nenhuma delas. Não somente Randolph inventa situações que evidenciam sua compreensão sofisticada da natureza do impostor e do homem irônico, mas, além disso, inclui em seu tratamento o gaiato (bomolochos) e o rústico (agroikos), nas cenas V e IV, respectivamente, este último apresentado como um caipira, isto é, um camponês com atitude de histrião e cujo discurso não vai além de sua natureza rural. Por outro lado, também introduz o gaiato, descrevendo-o como o outro extremo da urbanidade, um indivíduo satisfeito com seu próprio temperamento, embora não seja nada além de "as borras vis do escândalo" (the base dregs of scandal).

Róscio e os puritanos são os únicos personagens que permanecem no palco todo o tempo. No ato final, depois de contemplarem o espelho das musas, estes aderem à ideia de que os vícios não compensam. A despeito da reputação de Randolph e de seu sucesso na época, a peça sofre hoje inúmeras críticas. Segundo Riddell (1966, p. 110-111), trata-se de "uma peça com muito pouco mérito dramático". Ela é episódica, sem muita conexão entre os episódios e nem mesmo estes contêm desenvolvimento dramático, não passando de "exposições meramente superficiais de personagens, o conflito sendo bastante mecânico já que pares de personagens apenas declaram suas posições opostas". Sem a necessidade de discutir, aqui, o valor dramático da peça, uma vez que nosso interesse maior é compreender a imagem com

\footnotetext{
18 Wolfe (2008) considera difícil aceitar essa declaração automaticamente, já que o próprio Randolph (1638) nos adverte que Eiron sabe muito bem dissimular suas qualidades. 
a qual a comédia, de modo geral, é associada no período elisabetano, é preciso enfatizar que $O$ espelho das musas desempenha importante papel na controvérsia antiteatral que marcou esse período.

\section{O ESPELHO DA MUSA E A CONTROVÉRSIA ANTITEATRAL}

Inserida em uma verdadeira controvérsia sobre o valor do teatro, a peça $O$ espelho das musas funciona como uma resposta à alegação de que o palco é, por sua própria natureza, imoral e profano. A conclusão à que se chega pode ser resumida com a declaração de Róscio, um de seus personagens principais, de que o drama é moralmente superior ao sermão na mesma proporção em que os olhos são superiores aos ouvidos:

Ouso dizer, com coragem, Que colocamos mais sagacidade e virtude nas pessoas Com as risadas de uma peça, do que vinte tediosos sermões Conseguem salvar do pecado e da vida leviana E a causa disso é muito simples: Não se ganham as pessoas pelos ouvidos, mas pelos olhos! $!^{19}$

Jacobsen (1997, p. 285-293) trata detalhadamente dessa controvérsia e cita vários autores e pregadores da época que consideravam que as peças teatrais eram sermões diabolicamente invertidos e que o teatro era um consultório que Satanás usava para reunir os ímpios para a destruição. Além disso, a implicância dos puritanos com o teatro ultrapassava a ideia de que o drama consistia de uma espécie de paródia demoníaca do púlpito, uma vez que consideravam também que os dramaturgos invadiam seu território ao afirmar que, enquanto os sermões conseguiam apenas doutrinar os fiéis, o teatro conseguia instruir e deleitar a plateia. Ou seja, tratava-se de uma disputa moral e hermenêutica.

19 Boldly I dare say,

There has been more by us in some one play

Laugh'd into wit and virtue, than hath been

By twenty tedious lectures drawn from sin

And foppish humors, hence the cause doth rise:

Men are not won by th'ears so well as eyes. 
Em certo sentido, ao usar a imagem da comédia como espelho, Randolph secularizou uma metáfora comumente empregada pelos pregadores de sua época em relação à Bíblia. Apesar de seu contato com a tradição clássica, especialmente com relação ao uso que Ovídio e Diógenes Laércio fizeram do espelho para indicar o afastamento da alma da vaidade (Narciso) e a busca de autoconhecimento (Sócrates), respectivamente, a maioria das obras que incorporaram o espelho na Idade Média não passou de suplementos à ideia de que as Escrituras representam o espelho para o qual os leitores devem dirigir seu olhar. De acordo com Bradley (apud PIERCE, 1982, p. 2), os primeiros espelhos da Idade Média e da Renascença eram religiosos e incluíam "todos os pilares da doutrina cristã, abarcando todos os aspectos da vida que inspiravam a mente". Pierce (1982, p. 19-20) faz uma análise detalhada da presença do espelho na literatura clássica, bíblica e renascentista, chegando à conclusão de que "Ben Johnson e Thomas Randolph divorciaram as obras de espelho de suas origens cristãs... e criaram espelhos satíricos e cômicos de orientação clássica".

Para Pierce (1982, p. 155), a obra de Randolph se caracteriza por "uma leveza de toque e pela certeza de que os velhos valores e uma confortável via media são preferíveis ao autoexame rigoroso do puritanismo". Em última análise, deliberadamente secular e humanista, o espelho de Randolph sugere que o extremismo religioso geralmente conduz à estreiteza de mente. O espelho é a comédia! Róscio declara que "a alma vê a própria face / na comédia, e não tem outro espelho" (the soul sees her face / In comedy, and has no other glass). No primeiro ato, outro personagem, que acaba de ver Cólax no espelho, exclama: “Ora, então adeus! pois prefiro ver / O inferno do que um espelho ou comédia" (Nay then, farewell; for I had rather see / Hell than a looking-glass or comedy). Diante disso, Róscio responde:

E, contudo, não obstante, se não fosse pelo espelho, No qual a fisionomia da pessoa contempla sua graciosidade, Não haveria outro jeito de enxergar Quão próxima de Deus está a nossa face! $!^{20}$

20 And yet, nevertheless, if it 'twere not for the glass,

Wherein the form of man beholds his grace,

We could not find another way to see

How near our shapes approach divinity. 
Mais tarde, Róscio atribui a origem da comédia a Apolo na tentativa de curar as enfermidades humanas. ${ }^{21} \mathrm{O}$ deus toma a água da fonte das musas e a envia para $\mathrm{O}$ norte a fim de que seja transformada em cristal. Desse cristal Apolo faz um espelho para mostrar ao homem "Todas as deformidades, da alma e do corpo, / Para curar a ambas" (All his deformities, both of soul and body, / And cure them both). Temeroso de que o Hades ficasse despovoado por causa da invenção de Apolo, Pluto suplica às moiras que impeçam que o espelho dure mais do que um dia. As deusas the atendem o pedido, mas Apolo resgata o espelho danificado e o transforma na comédia. Daí a razão de serem as peças teatrais apresentações efêmeras.

No final da peça, os personagens puritanos sofrem uma metamorfose real em que passam a compreender o valor do drama. Flowerdew chama a peça dentro da peça de "o mais bendito dos espelhos" (a most blessed looking-glass). De modo significativo, enquanto isso, Temperance ("Moderação") dança com as virtudes. A mensagem de reprovação à hipocrisia e ao extremismo soa clara. Para Randolph, a comédia assume a função social de espelho apto a refletir os vícios da Inglaterra a fim de que sejam identificados e corrigidos. Com isso, provavelmente para o desespero de seus contemporâneos mais intransigentes, ele indica que o drama assume um papel tão ou mais vital que o da própria igreja que o condena e exclui.

A contribuição de Randolph à tradição religiosa do espelho é acrescentar que o speculum, inclusive o cômico, mostra para o ser humano que foi criado à imagem de Deus e que, portanto, é naturalmente capaz de praticar o bem. Segundo Pierce (1982, p. 159), "essa forma de ver o homem como reflexo da imagem de Deus acrescenta uma nova virada [twist] ao espelho ético de épocas anteriores". Shargel (1996) alude metaforicamente à tradição da narrativa psicológica como sendo a "igreja de Shakespeare", isto é, o cânon teatral ao qual o dramaturgo sempre foi fiel. No caso de Randolph, porém, é possível apontar, de forma muito mais literal, para a comédia

\footnotetext{
${ }^{21}$ De acordo com Pierce (1982, p. 169, n. 7), o mito apresentado por Róscio é uma criação original de Randolph. 
como sendo a sua igreja, uma igreja serena e espirituosa, capaz de inspirar a plateia a deixar sua própria mediocridade e buscar uma elevação natural e espontânea.

\section{CONCLUSÃO}

Embora influenciado por Ben Johnson e seus contemporâneos, não se pode dizer que Randolph tenha sido um dramaturgo típico de sua época. De fato, suas peças são mais vigorosamente filiadas à tradição clássica do que as daqueles cujo círculo ele frequentava. Para Shargel (1996, p. 166), Randolph foi "o único membro de sua tribo a resistir à nova suavidade da escrita urbana", escrevendo sob "o feitiço das gerações anteriores", o que fez com que sua comédia aludisse, com frequência, às peças de épocas passadas. Ele foi mais generoso com a recepção das obras de seus predecessores, especialmente as de origem clássica, do que seus sucessores foram em relação a sua contribuição, já por demasiado tempo condenada à obscuridade histórica.

De qualquer forma, $O$ espelho das musas nos revela o vívido interesse de um dramaturgo em livrar o teatro elisabetano do estigma social e, ao mesmo tempo, mostra que as antigas comédias áticas ainda encontravam lugar privilegiado no palco inglês. Se não por seus méritos dramáticos (e eles existem!), Randolph merece ser resgatado do anonimato ao menos pelo valor histórico de suas peças, pela contribuição acadêmica de sua compreensão do papel social da comédia e de uma recepção favorável à antiga comédia ática, e pelo modo como interpretou as teorias de Aristóteles e Teofrasto, delas se apropriando e se valendo.

\section{REFERÊNCIAS}

BUSH, Douglas. English literature of the earlier seventeenth century: 1660-1690. Oxford: Oxford University Press, 1946. 
COIRO, Ann Baynes. Anonymous Milton, or, A Maske Masked. English Literary History, v. 17, n. 3, p. 609-629, fall 2004.

DIBDIN, T. J. Charles. A complete history of the stage. London: Dibdin, 1800 ?

DIOMEDES. Arte gramatical: livro III. Tradução de Izabella L. Garbellini. Letras Clássicas, n. 9, p. 231-243, 2005.

DUPORT, James (Ed.). Poetical and dramatic works of Thomas Randolph. London: Ballantyne, 1875.

FARMER, Alan B. "Made like the times Newes": playbooks, newsbooks, and religion in Caroline England. Tese de doutorado em história do drama. Columbia University, 2005. $396 \mathrm{f}$.

FRESCOLN, Katharine P. Thomas Randolph: an Elizabethan in Scotland. Tese de doutorado em história. Universidade da Virgínia Ocidental, 1971. 524 f.

GREG, Walter W. Pastoral poetry and pastoral drama. New York: Russell \& Russell, 1910.

HALL, Edith. The English-speaking Aristophanes: 1650-1914. In: HALL, Edith; WRIGLEY, Amanda (Orgs.). Aristophanes in performance: 421 BC-AD 2007. Oxford: Legenda, 2007. p. 66-92.

HERRICK, Marvin T. Tragicomedy: its origin and development in Italy, France, and England. Urbana: University of Illinois Press, 1955.

JACOBSON, Kenneth R. Prophecy, performance, and persuasion: sermon art and dramatic art in England 1575-1630. Tese de doutorado em inglês. Ontario (Canadá), Queen's University, 1997. $433 \mathrm{f}$.

PIERCE JR., Charles S. The polished glass: a reading of selected mirror books of the English Renaissance. Tese de doutorado em inglês. Washington State University, 1982. $192 \mathrm{f}$. 
RANDOLPH, Thomas. The muses looking-glasse. Oxford: Leonard Lichfield, 1638.

. The muses looking-glasse. In: REED, Isaac; GILCHRIST, Octavius (Eds.). A select collection of old plays in twelve volumes. London: Septimus Prowett, 1825. p. 140-226.

RICHEK, Roslyn G. Thomas Randolph (1605-1635): Christian humanist, academic and London theater playwright. Tese de doutorado em filosofia. Norman, OK: Universidade de Oklahoma, 1982. $292 \mathrm{f}$.

RIDDELL, James $A$. The evolution of the humours characters in seventeenth-century English comedy. Tese de doutorado em inglês. University of South California, 1966. $253 \mathrm{f}$.

SAINTSBURY, George. A history of Elizabethan literature. London: Macmillan, 1905.

SHARGEL, Raphael. Shakespeare's church: an essay on narrative and identity. Tese de doutorado em inglês. Universidade da Virgínia, 1996. 427 f.

THORN-DRURY, G. The poems of Thomas Randolph. London: Frederick Etchells \& Hugh Macdonald, 1929.

WOLFE, Jessica. Chapman's ironic Homer. College Literature, v. 35, n. 4, p. 151-186, 2008. 